\title{
Cultivation of methanogenic community from subseafloor sediments using a continuous-flow bioreactor
}

\author{
Hiroyuki Imachi ${ }^{1}$, Ken Aoi ${ }^{1,2}$, Eiji Tasumi ${ }^{1}$, Yumi Saito ${ }^{1}$, Yuko Yamanaka ${ }^{1}$, Yayoi Saito ${ }^{1,2}$, \\ Takashi Yamaguchi ${ }^{2}$, Hitoshi Tomaru ${ }^{3}$, Rika Takeuchi ${ }^{3}$, Yuki Morono ${ }^{4}$, Fumio Inagaki ${ }^{4}$ \\ and Ken Takai ${ }^{1}$ \\ ${ }^{1}$ Subsurface Geobiology Advanced Research (SUGAR) Project, Extremobiosphere Research Program, Institute \\ of Biogeosciences, Japan Agency for Marine-Earth Science \& Technology (JAMSTEC), Yokosuka, Kanagawa, \\ Japan; ${ }^{2}$ Department of Environmental Systems Engineering, Nagaoka University of Technology, Nagaoka, \\ Niigata, Japan; ${ }^{3}$ Department of Earth and Planetary Sciences, University of Tokyo, Bunkyo-ku, Tokyo, Japan \\ and ${ }^{4}$ Geomicrobiology Group, Kochi Institute for Core Sample Research, JAMSTEC, Monobe B200, Nankoku, \\ Kochi, Japan
}

\begin{abstract}
Microbial methanogenesis in subseafloor sediments is a key process in the carbon cycle on the Earth. However, the cultivation-dependent evidences have been poorly demonstrated. Here we report the cultivation of a methanogenic microbial consortium from subseafloor sediments using a continuous-flow-type bioreactor with polyurethane sponges as microbial habitats, called down-flow hanging sponge (DHS) reactor. We anaerobically incubated methane-rich core sediments collected from off Shimokita Peninsula, Japan, for 826 days in the reactor at $10 \mathrm{C}$. Synthetic seawater supplemented with glucose, yeast extract, acetate and propionate as potential energy sources was provided into the reactor. After 289 days of operation, microbiological methane production became evident. Fluorescence in situ hybridization analysis revealed the presence of metabolically active microbial cells with various morphologies in the reactor. DNA- and RNA-based phylogenetic analyses targeting 16S rRNA indicated the successful growth of phylogenetically diverse microbial components during cultivation in the reactor. Most of the phylotypes in the reactor, once it made methane, were more closely related to culture sequences than to the subsurface environmental sequence. Potentially methanogenic phylotypes related to the genera Methanobacterium, Methanococcoides and Methanosarcina were predominantly detected concomitantly with methane production, while uncultured archaeal phylotypes were also detected. Using the methanogenic community enrichment as subsequent inocula, traditional batch-type cultivations led to the successful isolation of several anaerobic microbes including those methanogens. Our results substantiate that the DHS bioreactor is a useful system for the enrichment of numerous fastidious microbes from subseafloor sediments and will enable the physiological and ecological characterization of pure cultures of previously uncultivated subseafloor microbial life.
\end{abstract}

The ISME Journal (2011) 5, 1913-1925; doi:10.1038/ismej.2011.64; published online 9 June 2011

Subject Category: microbial ecology and functional diversity of natural habitats

Keywords: subseafloor sediment; methanogenesis; continuous-flow bioreactor

\section{Introduction}

Methanogenesis in subseafloor sediments is an important process in the planet's carbon cycle. A large quantity of methane is stored in the subseafloor as free gas, dissolved methane in the pore water or as hydrates and comprises approximately

Correspondence: H Imachi, Subsurface Geobiology Advanced Research (SUGAR) Project, Extremobiosphere Research Program, Institute of Biogeosciences, Japan Agency for Marine-Earth Science \& Technology (JAMSTEC), 2-15 Natsushima-cho, Yokosuka, Kanagawa 237-0061, Japan.

E-mail: imachi@jamstec.go.jp

Received 15 November 2010; revised 31 January 2011; accepted 14 April 2011; published online 9 June 2011
500-2500 Gt of methane carbon (Milkov, 2004). Subseafloor methane has also attracted attention as an energy resource, but methane is also a powerful greenhouse gas that is critical in the history of Earth's carbon cycle and climate changes (Schoell, 1988; Kvenvolden, 1995; Overpeck and Cole, 2006). Because isotopically light methane (that is, ${ }^{13} \mathrm{C}-$ depleted methane carbon) is globally distributed in subseafloor sediments, subseafloor methane may be largely mediated by microbial activities that cause enzymatic fractionation of carbon species (Milkov, 2004). Therefore, subseafloor microbial methanogenesis has been extensively investigated, largely with culture-independent molecular ecological techniques. 
Culture-independent molecular analyses have found a limited population of the known methanogenic Archaea (methanogens) groups in a variety of subseafloor sediments (see references in reviews by Fry et al. (2008); Inagaki (2010)). On average, methanogens represent only $0.1 \%$ population of the total archaeal 16S rRNA gene pool in deep subseafloor sediments (Fry et al., 2008). Methane-metabolizing archaeal populations also represent $<1 \%$ of the total biomass in Hydrate Ridge sediments based on the quantitative-PCR analysis of the methylcoenzyme $\mathrm{M}$ reductase (mcrA) gene (Colwell et al., 2008). Whereas, it has been hypothesized that subseafloor microbial methanogenesis might be driven by presently unidentified and/or uncharacterized life forms or via novel methanogenic pathways in subseafloor sediments (Inagaki et al., 2006). Thus, to clarify the significance of microbial methanogenesis in the subseafloor environments, the in situ methane-producing microbial entities need to be identified with the cellular and functional evidences. Cultivation of subseafloor methanogens is a significant challenge to such identification. However, traditional batch-type cultivation efforts have always encountered the strong resistance of the numerically dominating and/or functionally important microbial components in the subseafloor sediments (for example, D'Hondt et al., 2004; Toffin et al., 2004). Regarding to methanogens, only three methanogens have been successfully isolated and characterized from deep-sea sedimentary environments: Methanoculleus submarinus (Mikucki et al., 2003), Methanococcus aeolicus (Kendall et al., 2006) and Methanosarcina baltica (von Klein et al., 2002). In addition, Kendall and Boone (2006) reported that methanogenic enrichment cultures were obtained from anoxic marine sediments at Hydrate Ridge after a 2-year long-term incubation.

To effectively cultivate subseafloor microbes, including methanogens, we adopted a continuousflow bioreactor technique. The bioreactor used in this study is a down-flow hanging sponge (DHS) reactor originally developed for the treatment of municipal wastewater (for example, Agrawal et al., 1997; Tandukar et al., 2006; Uemura and Harada, 2010). A distinctive feature of the DHS reactor is the use of a polyurethane sponge to ensure the pore space of the medium, providing an enlarged surface area for microbial habitat and a longer cell residence time. In addition, continuous-flow-type cultivation can maintain substrates at low concentrations similar to those found in the natural environment. Continuous-flow also allows the outflow of metabolic products that may inhibit microbial growth if accumulated.

In this study, a methanogenic microbial community was successfully enriched from methane-rich subseafloor sediments using a newly designed DHS reactor. We also obtained ten anaerobic microorganisms in pure culture, including four methanogenic archaeal species, which were not cultivated directly from the natural subseafloor sediment samples but were readily cultivated from the enriched community in the reactor by conventional batch-type cultivation techniques.

\section{Materials and methods}

\section{Sediment core sampling}

In 2006, the shakedown cruise CK06-06 of the deepsea drilling vessel Chikyu was conducted at approximately $80 \mathrm{~km}$ offshore the Shimokita Peninsula of Japan, the northwestern Pacific. During the expedition, $365 \mathrm{~m}$ of sediment cores comprising a continuous record of the upper sedimentary section were recovered at Site C9001 $\left(41^{\circ} 10.6389^{\prime} \mathrm{N}\right.$, $142^{\circ} 12.081^{\prime} \mathrm{E}, \quad 1180 \mathrm{~m}$ water depth; Aoike and CK06-06 Scientists, 2007; Tomaru et al., 2009). For this study, we subsampled innermost sections (approximately $50 \mathrm{~cm}^{3}$ ) of the whole round cores from the sediment depths of $0.42,4.66,18.34,48.11$ and $106.7 \mathrm{mbsf}$ using a sterile tip-cut plastic syringe. We then made slurries of the sediments with $200 \mathrm{ml}$ autoclaved synthetic seawater (described below) without organic substances and neutralized $\mathrm{Na}_{2} \mathrm{~S} \cdot 9 \mathrm{H}_{2} \mathrm{O}$ solution under nitrogen gas. The subsampled sediments consisted of diatom-rich hemipelagic silty clay. All subsampling procedures were performed in a laminar flow clean bench onboard the Chikyu, and the sediment slurries were preserved at $4{ }^{\circ} \mathrm{C}$ in the dark until experiments were performed.

\section{DHS reactor and incubation of sediment}

A schematic diagram and movie of the DHS reactor are shown in Figure 1 and Supplementary Movie S1, respectively. The DHS reactor was constructed from a closed polyvinyl chloride (PVC) box (inside volume 10.7l) with polyurethane sponge-cubes $(3 \mathrm{~cm} \times 3 \mathrm{~cm} \times 3 \mathrm{~cm}$, pore size $0.83 \mathrm{~mm})$ as the carrier material for microbial cells. The spongecubes were encased in plastic nets to prevent crushing of the sponges. A total of 147 sponge carriers were randomly packed into the PVC box. The total pore volume of the sponges was $2.75 \mathrm{l}$, and this value was used for calculating the hydraulic retention time. The DHS reactor was operated under atmospheric pressure.

A mixture of the sediment slurry from multiple depths was used as the inoculum; that is, $20 \mathrm{ml}$ of 0.42 -mbsf sediment slurry, $50 \mathrm{ml}$ of each other sediment slurry and $230 \mathrm{ml}$ of synthetic seawater (described below) without any organic substances. The sponge-cubes were soaked with the mixed slurry manually and encased in the plastic net (Supplementary Figure S1). The encased sponges were then placed in the PVC box. This inoculation procedure was performed in a cold room maintained at $4{ }^{\circ} \mathrm{C}$, and the slurry and PVC box were flushed by 

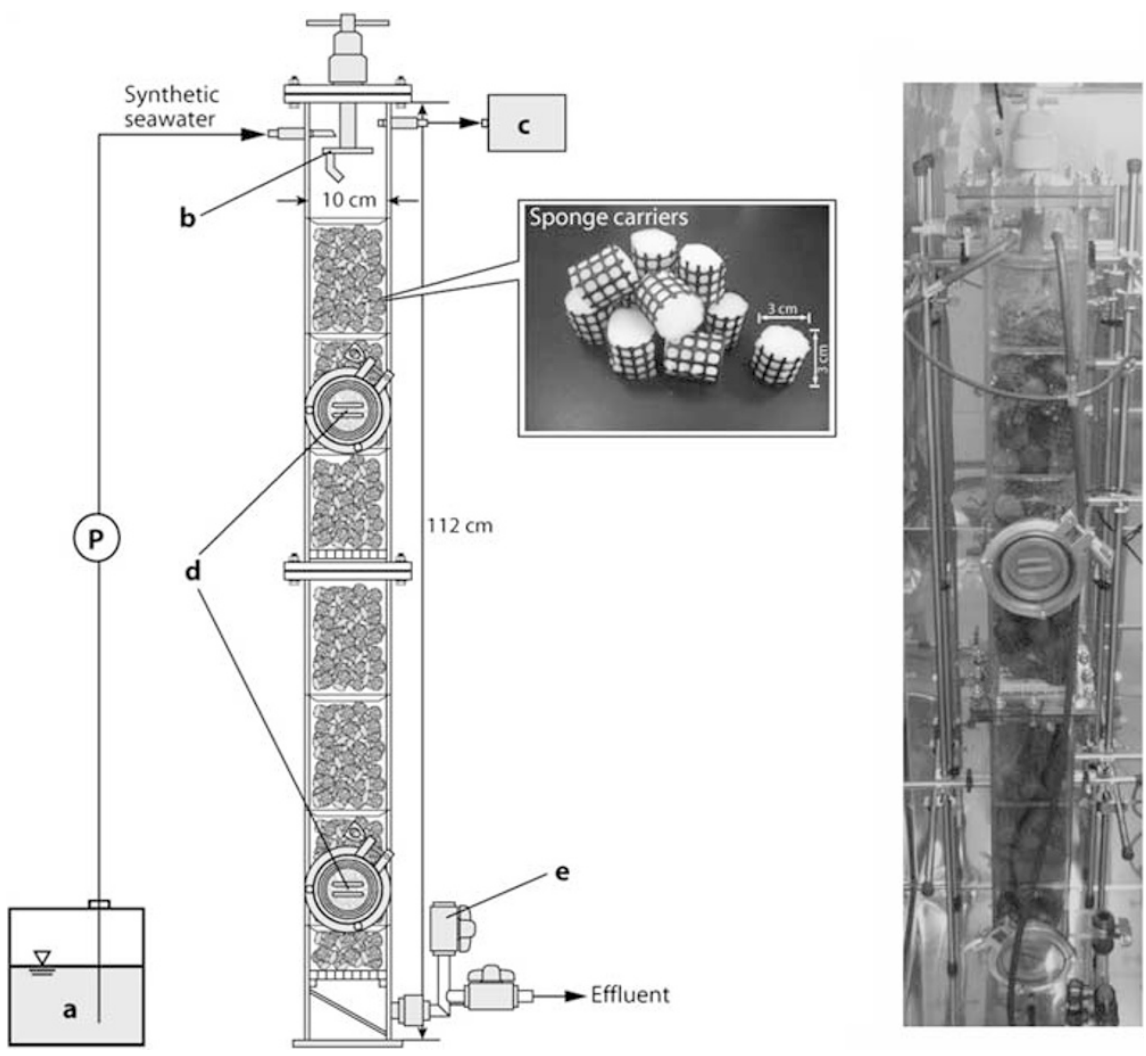

Figure 1 Schematic diagram and photographs of the DHS reactor used in this study. (a) Synthetic seawater tank, (b) distributor, (c) gas collecting bag, (d) sponge carrier sampling port and (e) port for the $\mathrm{pH} / \mathrm{ORP}$ sensor.

nitrogen gas at all times. After inoculation, the PVC box was tightly closed and installed in an incubator (M-600FN, Taitech, Koshigaya, Japan) in the dark at $10{ }^{\circ} \mathrm{C}$.

The composition of the synthetic seawater for the DHS reactor was the following $\left(\mathrm{l}^{-1}\right)$ : glucose, $85.45 \mathrm{mg}$; sodium acetate, $58.3 \mathrm{mg}$; propionate, $29.72 \mathrm{mg}$; yeast extract, $19.73 \mathrm{mg} ; \mathrm{NH}_{4} \mathrm{Cl}, 0.53 \mathrm{~g}$; $\mathrm{KH}_{2} \mathrm{PO}_{4}, 0.1 \mathrm{~g} ; \mathrm{MgCl}_{2} \cdot 6 \mathrm{H}_{2} \mathrm{O}, 4 \mathrm{~g} ; \mathrm{CaCl}_{2} \cdot 2 \mathrm{H}_{2} \mathrm{O}, 1 \mathrm{~g}$; $\mathrm{NaCl}, 25 \mathrm{~g} ; \mathrm{NaHCO}_{3}, 2 \mathrm{~g} ; \mathrm{Na}_{2} \mathrm{~S} \cdot 9 \mathrm{H}_{2} \mathrm{O}, 0.04 \mathrm{~g}$; trace element solution (Imachi et al., 2008), $1 \mathrm{ml}$; and vitamin solution (Imachi et al., 2009), $1 \mathrm{ml}$. 'Synthetic seawater' as used in this study is defined as synthetic seawater containing these organic substrates, unless otherwise mentioned. The synthetic seawater did not contain any sulfate salt. The final concentration of organic substrates was set at $200 \mathrm{mg}$ of chemical oxygen demand per liter, corresponding to $76.17 \mathrm{mg}^{-\mathrm{Cl}^{-1}}$ as the total organic carbon (the chemical component of yeast extract was assumed to be $\mathrm{C}_{5} \mathrm{H}_{7} \mathrm{NO}_{2}$ ). We used these organic substrates to enrich subseafloor methanogens because methanogens grow syntrophically with heterotrophic $\mathrm{H}_{2}$-producing bacteria via interspecies $\mathrm{H}_{2}$ transfer in many natural environments (see detailed explanation in Supplementary Text 1).

The synthetic seawater was purged by nitrogen gas, and pH was adjusted to 7.5. A total of $10 \mathrm{l}$ of synthetic seawater was made at a time. The 10-1 seawater bottle was stored at $10^{\circ} \mathrm{C}$. This anaerobic synthetic seawater was supplied into the reactor from the top inlet port by a peristaltic pump (Masterflex L/S tubing pump 7550-50, Cole-Parmer, Vernon Hills, IL, USA) with viton tubings (Cole-Parmer) and distributed to the sponge carriers by a distributor unit (Supplementary Figure S2). The synthetic seawater then flowed down, passing through the sponge carriers by gravity and was finally pumped out of the PVC box. The hydraulic retention time in the reactor was $84 \mathrm{~h}$, and the synthetic seawater was supplied intermittently by an automatic on/off timer (FT-011, Fine Inc., 1 min/ $29 \mathrm{~min}$ (on/off)) connected to the peristaltic pump to spread the seawater to the sponge carriers throughout the PVC box. In addition, the distributor unit was manually rotated at 3-day intervals to diffuse the seawater into all of the sponge carriers (Supplementary Figure S2). The gas phase in the reactor was sampled with an aluminum bag (AAK-5, Asone, Osaka, Japan) via viton tubing (Cole-Parmer) from the top portion of the reactor.

Chemical analysis and sampling from the DHS reactor Detailed chemical analysis method is described in the Supplementary Text 2. For microbial community analyses and batch-type cultivation experiments, sponge carriers were sampled at 357, 560 and 761 days of operation. At each sampling, two sponge carriers were collected from each sampling port 
(Figure 1), and $\mathrm{N}_{2}$ gas was flushed during the sampling (Supplementary Figure S3). After the sampling, sponge carriers were immediately soaked in the anaerobic synthetic seawater, and sediments were removed from the sponge carriers by manual rubbing in the anaerobic synthetic seawater without organic compounds.

Nucleic acid extraction, PCR, cloning and phylogenetic analysis

Detailed methods of DNA and RNA extractions, PCR amplification and clone library construction are described in the Supplementary Texts 2 and 3. Recovered 16S rRNA and its gene clone sequences were classified into each phylotypes by a threshold of $97 \%$ sequence similarity. Representative phylotypes of mcrA as well as 16S rRNA and its gene sequences were subjected to similarity analysis with the BLAST program (Altschul et al., 1997). The names of the phylotypes obtained from the inoculum sediment sample and enrichment samples in the DHS reactor are indicated by $\mathrm{xxxD}$ (or R)_A(or B or mcrA)yy (where $\mathrm{x}=$ sampling day, $\mathrm{D}=\mathrm{DNA}$ based library, $\mathrm{R}=\mathrm{RNA}$-based library, $\mathrm{A}=$ archaeal clone, $\mathrm{B}=$ bacterial clone, $\mathrm{mcr} \mathrm{A}=\mathrm{mcr} \mathrm{A}$ clone and $\mathrm{y}=$ phylotype number). The names of the phylotypes obtained from the batch-type cultures are indicated by $\mathrm{xxx} \_\mathrm{A}$ (or $\mathrm{B}$ ) $\mathrm{y}$ (where $\mathrm{x}=$ culture name, $\mathrm{A}=$ archaeal clone, $\mathrm{B}=$ bacterial clone and $\mathrm{y}=$ phylotype number). The phylogenetic analysis of the 16S rRNA gene sequence obtained was performed as described previously (Imachi et al., 2006). A deduced McrA amino-acid sequence-based phylogenetic tree was constructed by the neighborjoining method in the ARB program (Ludwig et al., 2004) with 168 amino acid positions and the percentage of acceptance of mutations distance correction. The sequences reported in this study have been deposited in the GenBank/EMBL/DDBJ database under accession numbers AB598074 to AB598076, AB598144 to AB598294 and AB598555.

\section{Real-time PCR quantification}

Quantitative real-time PCR was performed using SYBR Green I fluorescent dye as described previously (Lipp et al., 2008). For archaeal and bacterial $16 \mathrm{~S}$ rRNA gene amplifications, the primer sets ARC806F/ARC958R and Bac27F/EUB338R-I were used, respectively.

\section{Fluorescence in situ hybridization (FISH)}

Detailed sample fixation method and hybridization procedure are described in the Supplementary Text 2. The 16S rRNA-targeted oligonucleotide probes used in this study are shown in the Supplementary Table S1. To estimate the effectiveness of probes RC-III131, MBGB-380 and MBGD318, which targeted environmental sequence groups, the Clone-FISH method (Schramm et al., 2002) was performed according to a previously described protocol (Kubota et al., 2006). The plasmid-inserted sequences for the Clone-FISH were obtained from the sediment slurries used in this study and from methane seep sediments of the Nankai Trough stored in our laboratory. The clonal sequences used for the Clone-FISH were AB598074 to AB598076. Oligonucleotide probes were labeled with Cy-3, Alexa Fluor 555 or Alexa Fluor 488. To distinguish microbial cells in sediment slurry samples, the samples were counterstained with $4^{\prime}$,6-diamidino-2-phenylindole $\left(1 \mu \mathrm{g} \mathrm{ml}^{-1}\right.$ for $5 \mathrm{~min}$ at room temperature) after all of the in situ hybridization steps.

\section{Batch-type cultivation}

To isolate anaerobic microorganisms grown in the DHS reactor, batch-type cultivation was performed in $50-\mathrm{ml}$ serum vials containing $20 \mathrm{ml}$ media under an atmosphere of $\mathrm{N}_{2}-\mathrm{CO}_{2}(80 / 20(\mathrm{v} / \mathrm{v}))$ without shaking. The basal medium was the synthetic seawater used for the DHS reactor cultivation without organic compounds and contained one of the following energy sources: (i) each of the organic substrates in the synthetic seawater (that is, glucose, yeast extract, acetate and propionate); (ii) each of the methanogenic substrates, such as $\mathrm{H}_{2}$, formate, trimethylamine, methanol and 2-propanol; or (iii) each of the fermentation intermediates from glucose and yeast extract, such as ethanol, lactate and butyrate. We also tested the media in the presence and absence of antibiotics (that is, ampicillin, vancomycin, kanamycin and rifampicin) to obtain archaeal cultures that might be outcompeted by the bacterial populations. Each antibiotic was added to the media at a final concentration of $50 \mu \mathrm{g} \mathrm{ml}^{-1}$. For the cultivation of hydrogenotrophic methanogens using $\mathrm{H}_{2}$ and formate, $0.01 \%(\mathrm{w} / \mathrm{v})$ yeast extract and $1 \mathrm{mM}$ acetate were added to the media. Initially, approximately $2 \mathrm{ml}$ of the enrichment sediment slurry samples that were collected at 560 and 761 days of operation were inoculated into each medium (Supplementary Figure S3). All of the cultures were incubated at $10^{\circ} \mathrm{C}$, except for the cultivation of acetate-, propionate- and butyrate-utilizing anaerobes, for which prepared cultures were incubated at $25{ }^{\circ} \mathrm{C}$ because of their slow growth (for example, Imachi et al., 2007). Isolation of microorganisms from the enrichment cultures was conducted by serial dilution in liquid culture and/or roll-tubes. The purity of the isolate was routinely checked by microscopy.

As a reference to the continuous-flow-type cultivation using the DHS reactor, conventional batch-type cultivation was also performed from the natural mixed sediment slurry using $\mathrm{H}_{2}$ (approximately $150 \mathrm{kPa}$ in the head space), formate $(20 \mathrm{mM})$, methanol $(10 \mathrm{mM})$, acetate $(5 \mathrm{mM})$, butyrate $(10 \mathrm{mM})$ or propionate $(10 \mathrm{mM})$ as the energy source. The 
reference cultivations were performed at $10^{\circ} \mathrm{C}$, in $100 \mathrm{ml}$ serum vials containing $30 \mathrm{ml}$ medium under an atmosphere of $\mathrm{N}_{2}-\mathrm{CO}_{2}(80 / 20$, (v/v)) without shaking. The basal medium was the same composition as in the isolation works described above. A total of $10 \mathrm{ml}$ of the sediment slurry was inoculated into each serum vial. The culture vessels were set up in duplicate for each substrate. The serum vials were sealed with butyl rubber stoppers and aluminum crimp seals. To monitor anaerobic conditions in the media, resazurin was added to the medium as a redox indicator.

\section{Microscopy}

An Olympus microscope (Olympus BX51F, Olympus, Tokyo, Japan) with a color CCD camera system (Olympus DP72) was used for the studies of cell morphology and epifluorescence.

\section{Results}

Microbial metabolism and activities during enrichment in the DHS reactor

We operated the DHS reactor at $10^{\circ} \mathrm{C}$ for 826 days. The average oxidation-reduction potential (ORP) value of the effluent seawater was $-287 \mathrm{mV}$ (s.d. $\pm 56 \mathrm{mV}, n=677$ ), indicating that reductive conditions were maintained in the reactor during operation (Supplementary Figure S4a). The average $\mathrm{pH}$ value was 7.4 (s.d. \pm 0.1 ; Supplementary Figure S4b). We also analyzed the chemical characteristics of effluent seawaters and gases at an approximately 2-month interval after 179 days (Table 1). Complete consumption of glucose was observed in all of the samples examined. Acetate accumulation, probably because of microbial fermentation of glucose and/or yeast extract, was observed in all of the samples examined, whereas acetate consumption was evident after 631 days based on the decrease in acetate concentration. No methane was detected before day 179. A small amount of dissolved methane was detected in the effluent seawater of 179- and 230-day samples. Methane was first observed in the gas phase of the reactor at $1.5 \mathrm{mg}$ $\mathrm{Cl}^{-1}$ at 289 days. The methane concentration subsequently increased up to $10.1 \mathrm{mg}-\mathrm{Cl}^{-1}$ by day 560 and fluctuated between $3.6 \mathrm{mg}^{-\mathrm{Cl}^{-1}}$ and $9.0 \mathrm{mg}-\mathrm{Cl}^{-1}$ after 631 days. The stable carbon isotope compositions of methane and $\mathrm{CO}_{2}$ in the gas phase of the reactor were between $-60.1 \%$ and $-78.1 \%$ o and between $-14.7 \%$ and $-15.9 \%$, respectively. These values strongly indicate that microbial methanogenesis occurred (for example, Whiticar, 1999). We also provided propionate as a substrate, but distinct degradation of propionate was not observed until after 631 days. Any other potential fermentation intermediates such as lactate, succinate, fumarate, malate, ethanol and butyrate were not detected in the effluent seawater. The carbon mass balance was inconsistent between the influent and effluent; this inconsistency was particularly pronounced after 420 days of operation. This carbon mass imbalance may be due to the escape of dissolved carbon such as carbon dioxide produced by microbial methanogenesis and fermentation. These data indicate the existence of a methanogenic microbial community in the DHS reactor.

\section{Abundance of Archaea and Bacteria estimated by quantitative real-time PCR}

In the inoculum sediment slurry, the relative abundance of archaeal and bacterial 16S rRNA genes was found to be $2.9 \%$ and $97.1 \%$, respectively (Supplementary Table S2). However, in the enrichment samples from the DHS reactor, the relative abundance of archaeal rRNA genes was consistently

Table 1 Changes of substance concentrations during the DHS reactor operation

\begin{tabular}{|c|c|c|c|c|c|c|c|c|c|c|c|c|}
\hline & \multirow{2}{*}{$\begin{array}{l}\text { Theoretical values } \\
\text { of influent }\end{array}$} & \multicolumn{11}{|c|}{ Sampling day of effluent seawaters and gases } \\
\hline & & 179 & 230 & 289 & 357 & 420 & 491 & 560 & 631 & 693 & 761 & 826 \\
\hline TOC $\left(\mathrm{mg}-\mathrm{Cl}^{-1}\right)$ & 76.17 & 59 & 69 & 52 & 68 & 17 & 42 & 45 & 17 & 16 & 21 & 23 \\
\hline Glucose (mg-Cl-1) & 34.18 & 0 & 0 & 0 & 0 & 0 & 0 & 0 & 0 & 0 & 0 & 0 \\
\hline Yeast extract $\left(\mathrm{mg}-\mathrm{Cl}^{-1}\right)^{\mathrm{a}}$ & 10.47 & - & - & - & - & - & - & - & - & - & - & - \\
\hline Acetate $\left(\mathrm{mg}-\mathrm{Cl}^{-1}\right)$ & 17.06 & 31 & 36 & 28 & 40 & 28 & 31 & 23 & 16 & 20 & 18 & 10 \\
\hline Propionate $\left(\mathrm{mg}-\mathrm{Cl}^{-1}\right)$ & 14.46 & 12 & 19 & 11 & 18 & 11 & 12 & 12 & 7 & 8 & 6 & 5 \\
\hline Dissolved $\mathrm{CH}_{4}$ in effluent (mg-Cl ${ }^{-1}$ ) & & 0.01 & 0.02 & - & 0.1 & 0.2 & 0.3 & 0.4 & 0.3 & 0.3 & 0.4 & 0.2 \\
\hline $\mathrm{CH}_{4}$ in gas phase $\left(\mathrm{mg}-\mathrm{Cl}^{-1}\right)$ & & 0 & 0 & 1.5 & 3.5 & 3.6 & 8.4 & 10.1 & 8.0 & 5.9 & 9.0 & 3.6 \\
\hline Carbon balance $(\%)^{\mathrm{b}}$ & & 77 & 91 & 69 & 89 & 22 & 55 & 59 & 22 & 21 & 28 & 30 \\
\hline$\delta^{13} \mathrm{C}^{-} \mathrm{CH}_{4}(\%)^{\mathrm{c}}$ & & - & - & - & -74.9 & -78.1 & -64.5 & -60.1 & -60.9 & -61.7 & -62.8 & -64.4 \\
\hline$\delta^{13} \mathrm{C}-\mathrm{CO}_{2}(\%)^{\mathrm{c}}$ & & - & - & - & -15.5 & -15.0 & -15.6 & -15.7 & -15.7 & -14.7 & -15.5 & -15.9 \\
\hline
\end{tabular}

Abbreviations: DHS, down-flow hanging sponge; TOC, total organic carbon.

${ }^{a}$ Yeast extract was calculated on the assumption that the chemical component is $\mathrm{C}_{5} \mathrm{H}_{7} \mathrm{NO}_{2}$.

'The values of carbon balance were calculated by dividing total effluent-TOC including methane gases' TOC by total theoretical influent-TOC.

cThese values were obtained gases in the gas collection bag.

-, not measured (it assumed that yeast extract was completely degraded in the DHS reactor). 

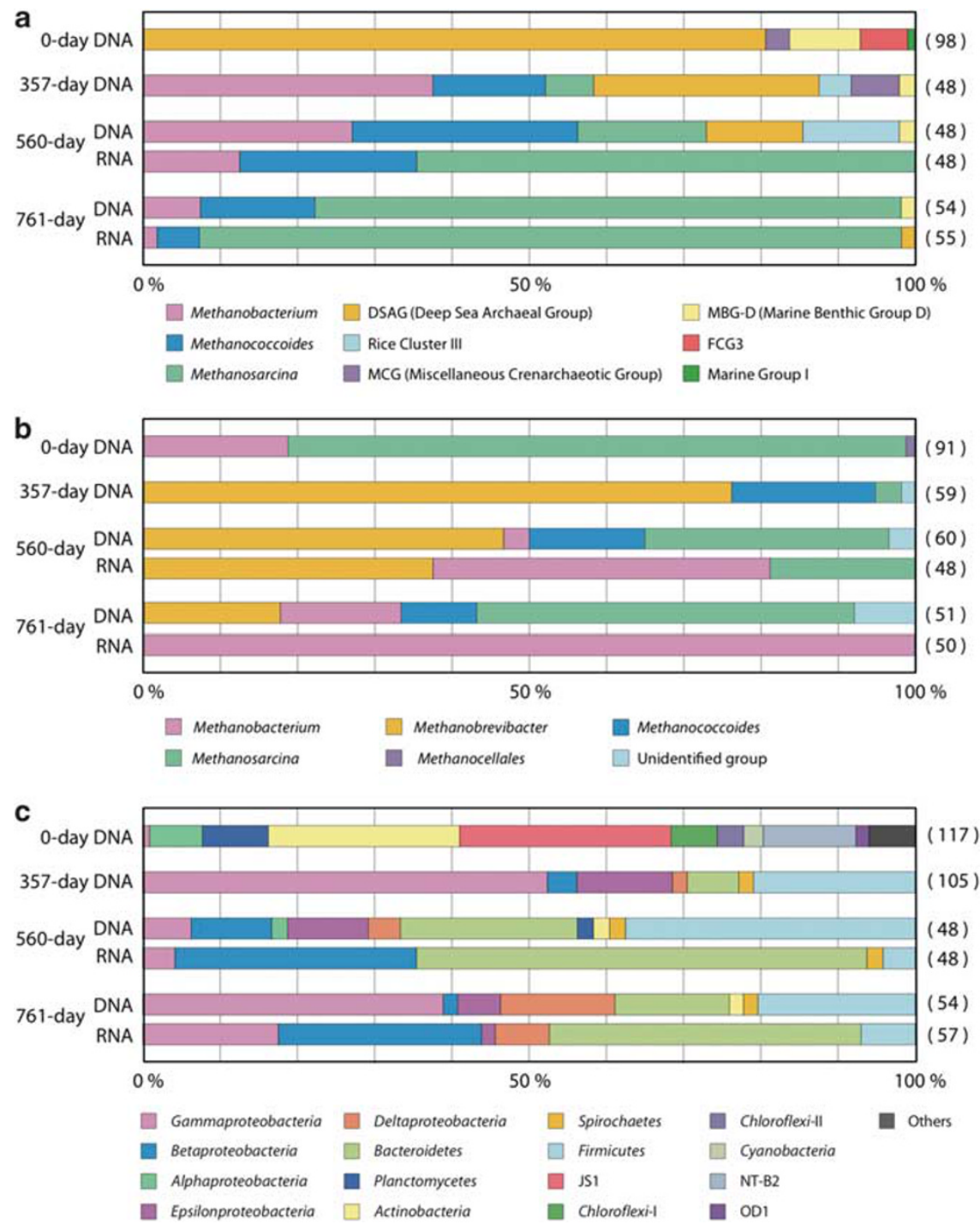

Figure 2 Archaeal, methanogens and bacterial composition shown by clone analyses. Clonal composition of (a) archaeal 16S rRNA and its gene, (b) mcrA mRNA and its gene and (c) bacterial 16S rRNA and its gene. Clone libraries were constructed from RNAs only made from the 561-day and 761-day samples. The numbers of sequenced clones in each clone library are shown in parentheses.

lower $(0.005 \%, 0.009 \%$ and $0.009 \%$ at the 357,560 and 761 days of operation, respectively).

\section{Composition of the microbial community in the DHS} reactor

To characterize the composition of the microbial community and the community shifts during the enrichment, we constructed clone libraries targeting the 16S rRNA and mcrA genes using samples from before and after the enrichment (Figure 2 and Supplementary Figures S5-S7, Supplementary Tables S3-S7). To identify the active microbial components, we also made clone libraries using RNA extracts obtained from the 560- and 761-day samples using reverse transcription PCR.

All of the archaeal rRNA gene phylotypes detected in the inoculum sediment sample (that is, 0-day sample in Figure 2) were closely related to the environmental phylotypes previously reported from various subseafloor sediments, such as Deep-Sea Archaeal Group (alternatively designated as Marine Benthic Group-B), Marine Benthic Group-D and Miscellaneous Crenarchaeotic Group (Figure 2a and Supplementary Figure S5, Supplementary Tables S3 and S4). Among the 98 archaeal clone sequences in the inoculum sample, none of the known methanogen-related sequences were detected. During the enrichment in the DHS reactor, the archaeal composition was drastically shifted. The predominant archaeal phylotypes at 357 days (58.3\% of the clones examined) were closely related to the sequences of previously isolated methanogens such as Methanobacterium, Methanococcoides and Methanosarcina members, with high sequence similarities (>98\%) (Supplementary Table S5). 
The clonal abundance of those methanogen-related phylotypes increased throughout the DHS reactor operation. In particular, the phylotype 357D_A5, related to the genus Methanosarcina, sharply became abundant during the DHS reactor cultivation (76.0\% and $90.9 \%$ of the clones examined in the 761-day DNA and 761-day RNA-based libraries, respectively).Among the potentially methanogenic phylotypes, the phylotype 357D_A3 was closely related to the methylotrophic methanogen group Methanococcoides. This result implied that the microorganism might utilize methylamines eluted as secondary products from the sediments (Liu and Whitman, 2008). In fact, we detected trimethylamine in the effluent seawaters at 560 and 761 days, although the concentrations were below the quantification limit $\left(<0.1 \mathrm{mg} \mathrm{l}^{-1}\right)$. We also measured methanol and monomethylamine, which are substrates for known members of the genus Methanococcoides, but they could not be detected in the effluent seawaters. In addition to the known methanogen-related phylotypes, we also detected phylotypes belonging to uncultured archaeal lineages such as Rice Cluster III, Marine Benthic Group-D and Deep-Sea Archaeal Group after the DHS reactor operation. However, the clonal abundance of the Deep-Sea Archaeal Group group drastically decreased relative to the methanogenrelated phylotypes composition during the DHS reactor operation.

McrA gene clones were analyzed to further characterize the compositional and functional transitions of the methanogenic components (Figure 2b). The mcrA genes were successfully amplified from all of the samples. In the inoculum sample, the recovered phylotypes were affiliated with the genera Methanobacterium and Methanosarcina and the order Methanocellales (Figure 2b and Supplementary Figure S6, Supplementary Table S4). In contrast, during the enrichment, the mcrA gene phylotypes were potentially affiliated with not only the Methanobacterium and Methanosarcina groups but also the Methanobrevibacter and Methanococcoides groups (Supplementary Table S6). All of these mcrA sequences had $>90 \%$ similarity to those of previously cultivated methanogens. We also detected an unidentified mcrA phylotype (357D_mcrA4). The $\mathrm{H}_{2}$-utilizing methanogen group within the genus Methanobrevibacter (phylotype 357D_mcrA1) dominated in the early phase of enrichment, comprising $76 \%$ of the total clones in the 357-day library, but its relative abundance decreased gradually in the course of DHS reactor operation. In contrast, the relative abundances of Methanobacterium and Methanosarcina phylotypes increased; that is, they accounted for from $0 \%$ to $15.6 \%$ and $3.4 \%$ to $49 \%$, respectively, in the DNAbased clone libraries. In the 761-day RNA library, only the single Methanobacterium phylotype 560R_mcrA was detected (Figure 2b and Supplementary Table S6). Repeating the construction of the clone library of the RNA extract from day 761 yielded the same results, which was inconsistent with the result obtained with the archaeal 16S rRNA from RNA extract from day 761. This inconsistency may be caused by possible biases associated with PCR amplification and cloning (for example, von Wintzingerode et al., 1997).

The predominant bacterial 16S rRNA gene phylotypes observed in the inoculum sample were related to members of the phyla Chloroflexi, Planctomycetes and Actinobacteria, candidate phyla JS1 and NT-B2 and the class Alphaproteobacteria, which have been frequently detected as the predominant bacterial components in various subseafloor sediments (for example, Fry et al., 2008; Inagaki, 2010; Figure 2c and Supplementary Figure S7, Supplementary Table S4). During cultivation in the DHS reactor, the composition of bacterial rRNA gene phylotypes changed drastically. The shift in the bacterial phylotype composition before and after cultivation supports the definite but selective cultivation of bacterial populations representing indigenous subseafloor bacterial components. The phylotypes within the classes Gammaproteobacteria and Betaproteobacteria and the phyla Bacteroidetes and Firmicutes dominated, and none of the sequences that were detected in the inoculum sediment was detected in the enrichment samples (Figure 2c and Supplementary Figure S7, Supplementary Table S7). The 21 phylotypes of $16 \mathrm{~S}$ rRNA genes among the total 46 bacterial phylotypes from the enrichment samples were highly similar $(>97 \%)$ to the sequences of the environmental clones and cultures that were obtained from the marine or terrestrial subsurface environments (Supplementary Table S7). In addition, many phylotypes (357D_B1, 357D_B3 to _B6, 357D_B9 to B12, 357D_B14, 357D_B17, 357D_B20, 357D_B22, 560D_B7, 560D_B13, 560R_B6) were closely related to anaerobic bacterial species that utilize glucose and/or yeast extract, which was consistent with the chemical data indicating the occurrence of glucose (and yeast extract) fermentation during the enrichment in the reactor (Supplementary Table S7). The bacterial phylotype composition also suggested the occurrence of aerobic and/or microaerophilic bacteria (phylotypes 357D_B7, 357D_B8, 357D_B18, 357D_B19, 357D_B21, 560D_B10, 761D_B9, 761R_8 and 761R_B14; Supplementary Table S7). Although the ORP values clearly indicated the reductive condition of the effluent seawater (Supplementary Figure S4a), the PVC box and viton tubing of the reactor system could conceivably be sources of oxygen from air because they are made of oxygenpermeable materials. When synthetic seawater containing resazurin, a redox indicator, was fed into the DHS reactor, the synthetic seawater was faintly colored pink at the top of the PVC box while the effluent seawater from the PVC box became colorless again. Thus, molecular oxygen may have contaminated the viton tubing before entering the PVC box 

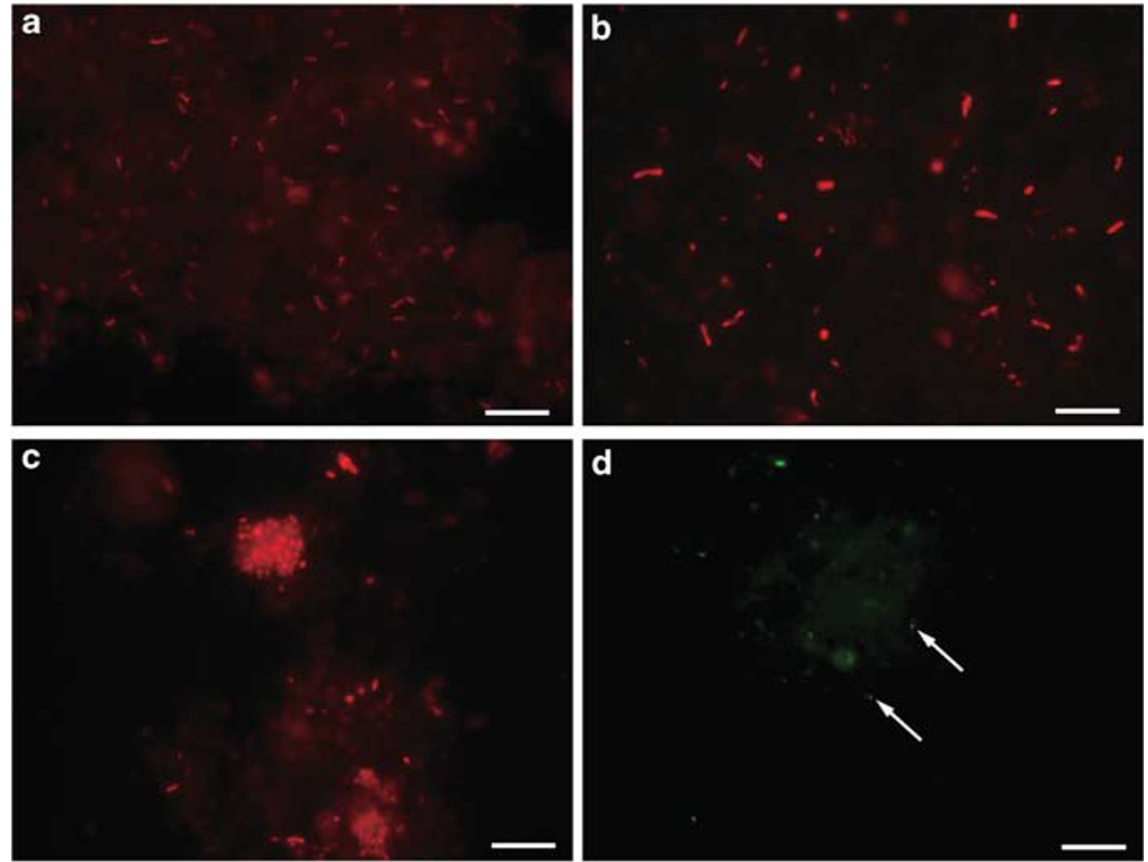

Figure 3 FISH images of the methanogenic consortium cultivated in the DHS reactor. Fluorescence photomicrographs (a-c) and (d) were obtained by the standard FISH and CARD-FISH analyses, respectively. (a) 560-day sample hybridized with the Alexa Fluor 555-labeled Archaea domain-specific probe ARC915, (b, c) 357-day sample hybridized with a Cy-3-labeled Bacteria domain-specific probe EUB338* and (d) CARD-FISH with a probe ARC915 showing fairly small coccoid cells (approximately $200-400 \mathrm{~nm}$ in diameter) in the 560-day sample. Cells indicated by an arrow were stained by both the ARC915 probe and 4',6-diamidino-2-phenylindole. Bars represent $10 \mu \mathrm{m}$.

and could be consumed by existing aerobic microbial activities during the retention of the synthetic seawater in the sponge carriers.

Detection of microbes in the DHS reactor using FISH The metabolically active microorganisms enriched in the DHS reactor were confirmed by FISH analysis of the sediments before and after the reactor operation. In the inoculum sample, signals were not identified using either the universal archaeal probe ARC915 or the universal bacterial probe EUB338*. In contrast, we obtained positive signals using these probes from all of the enriched sediment samples that were collected at 357, 560 and 761 days (Figure 3). All of the ARC915 probe-hybridized cells were rods (Figure 3a), while the EUB338* probereacted cells were morphologically variable (Figures $3 \mathrm{~b}$ and 3c). Based on morphological features of the ARC915-positive cells and the composition of $16 \mathrm{~S}$ rRNA and mcrA phylotypes in the enriched samples, we expected that the rod-shaped archaeal cells were members of the genera Methanobacterium and/ or Methanobrevibacter. Thus, further FISH analysis using two different probes of ARC915 and MB1174 was conducted. Almost all of the ARC915-reactive rod-shaped cells gave positive signals with the MB1174 probe (data not shown). Positive signals using other genus- and group-specific oligonucleotide probes (targeting Methanococcoides, Methanosarcina, Rice Cluster III, Deep-Sea Archaeal Group and Marine Benthic Group-D) were not obtained from the enrichment samples. In the CARD-FISH analysis using the ARC915 probe, we found very small coccoid-shaped cells (diameter, approximately 200-400 nm) present in the enrichment samples at 560 and 761 days of operation (Figure 3d). These small cells were presumably less active than the possible Methanobacterium and Methanobrevibacter populations but may represent different archaeal populations enriched in the DHS reactor.

\section{Isolation of anaerobic microorganisms from the DHS} reactor

To obtain pure cultures of anaerobic microorganisms, including methanogens, in the DHS reactor, conventional batch-type cultivation techniques were used. Most of the cultivation tests were conducted using the 560-day sample as an inoculum, while the cultivation of acetate- and propionate -utilizing anaerobes used the 761-day sample because the acetate and propionate degradation were clearly evident after the 631 days of operation (Table 1).

The cellular growth and substrate consumption or acid production in all of the primary cultures were confirmed after 2-8 months of incubation (Supplementary Table S8). Methane production was observed in many of the cultures, except when glucose, yeast extract or lactate were the sole energy 
and carbon sources. Microscopic observation showed that these methane-producing cultures contained cells having $\mathrm{F}_{420}$-like autofluorescence, indicating the presence of methanogens. In particular, $\mathrm{F}_{420}$-autofluorescent cells became the predominant population in all of the hydrogen- and formate-fed cultures (more than $80 \%$ of the total microbial cells). The propionate-, ethanol- and butyrate-fed cultures contained microorganisms of various morphology types together with $\mathrm{F}_{420^{-}}$ autofluorescent cells (that is, methanogens). The microscopic observations and the concomitant substrate consumption and methane production in the propionate-, ethanol- and butyrate-fed cultures suggested syntrophic growth on these organic substrates by hydrogenogenic organotrophic bacteria and hydrogenotrophic methanogens (Schink, 1997; Stams and Plugge, 2009). All of the cultures were successively transferred into fresh medium with $5 \%$ to $20 \% \quad(\mathrm{v} / \mathrm{v})$ inoculation. As the enrichment progressed, almost all of the cultures grew faster than the primary cultures. However, three cultures supplemented with acetate or propionate (cultures Ace10, AYEAV10 and Prop10) exhibited unstable growth, such as an unexpectedly long lag time ( $>6-8$ months) for growth and stagnation of growth. Thus, molecular analyses of these cultures have not yet performed.

To identify the microorganisms in the batch-type cultures, we performed 16S rRNA gene-based clone analyses using DNA that was extracted from cultures successively transferred more than three times. Only bacterial 16S rRNA genes were obtained by PCR from the glucose-, yeast extract- and lactate-fed cultures, while both archaeal and bacterial $16 \mathrm{~S}$ rRNA genes were obtained from the other cultures. The clone analysis revealed that phylogenetically diverse microorganisms were successfully cultivated in the batch-type cultures after the DHS reactor enrichment (Supplementary Table S8, Supplementary Figures S5-S7). A total of 38 phylotypes were obtained, and 24 phylotypes had sequences identical to those of the phylotypes that were detected in the first enrichment samples in the DHS reactor.

To isolate microorganisms found in the batch-type cultures, we performed serial dilution in both liquid and solid media. We successfully isolated four methanogens (Figure 4) and six anaerobic bacteria (Figure 5) in pure culture (see also Supplementary Table S8, Supplementary Figures S5-S7).

As a control experiment, the same natural subseafloor mixed sediments used for the DHS reactor cultivation were directly incubated in serum vials with $\mathrm{H}_{2}$, formate, methanol, ethanol, butyrate and propionate. However, neither growth nor chemical changes were observed after 850 days of incubation, while as a positive control, Methanococcus aeolicus (DSM 17508) and Methanosarcina semesiae (DSM 12914) could grow in the same media.

\section{Discussion}

We applied a continuous-flow bioreactor system (DHS reactor) to cultivate a methanogenic microbial community from subseafloor sediments. Using the DHS reactor system as the first step of cultivation, we successfully obtained phylogenetically diverse microorganisms including methanogens, while no growth was observed in conventional batch-type cultivation experiments using the same inoculum. Compared with previous conventional batch-type cultivation efforts that yielded only a few methanogen cultures from subseafloor sediments (von Klein et al., 2002; Mikucki et al., 2003; Kendall and Boone, 2006; Kendall et al., 2006) and the results of our reference experiments, cultivation using the continuous-flow DHS reactor system appears very useful for cultivating the numerous fastidious microbial components in the subseafloor sedimentary biosphere.

Other reports confirm the usefulness of continuous-flow-type cultivation techniques like the DHS reactor presented in this study for the cultivation of fastidious microbial populations from natural environments. For example, several types of continuous-flow bioreactor systems have been developed and applied for the enrichment and cultivation of archaeal anaerobic methanotrophs (Girguis et al., 2003, 2005; Meulepas et al., 2009; Zhang et al., 2010). Girguis et al., (2003, 2005) developed a continuous-flow incubation system to mimic the in situ conditions of methane seep marine sediments and reported an increase in the archaeal anaerobic methanotroph population associated with the anaerobic oxidation of methane in the incubation system. Meulepas et al., (2009) also demonstrated that the oxidation of methane rate in a continuous submergedmembrane bioreactor increased exponentially from 0.4 to $286 \mu \mathrm{mol} \mathrm{g} \mathrm{dry}^{-1}$ weight day $^{-1}$, clearly demonstrating the metabolically activated and enriched oxidation of methane consortium in the reactor.

In this study, we used polyurethane sponges as an artificial habitat for sedimentary microbes, which appear to be ideal for cultivating subseafloor microorganisms. The porous sponge mimics the porous layers (ash and sand layers) of the subseafloor sediments. Inagaki et al., (2003) and Kobayashi et al., (2008) reported that cultivable microbial components were generally more numerous in the porous layers than in the pelagic clay layers. In addition, the distinguishing feature of the DHS reactor is that the sponges are not submerged and freely placed in the atmosphere (Uemura and Harada, 2010). Therefore, in the DHS reactor, the influent seawater flows down into the sponges by gravity, permitting the effective exchange of the synthetic seawater fluid not only on the surface of but also inside the sponge. These advantages allow the DHS bioreactor system to yield a greater biomass in the reactor than other continuous-flow systems (Tandukar et al., 2006), faciliating subsequent batchtype cultivation of the enriched microorganisms. 

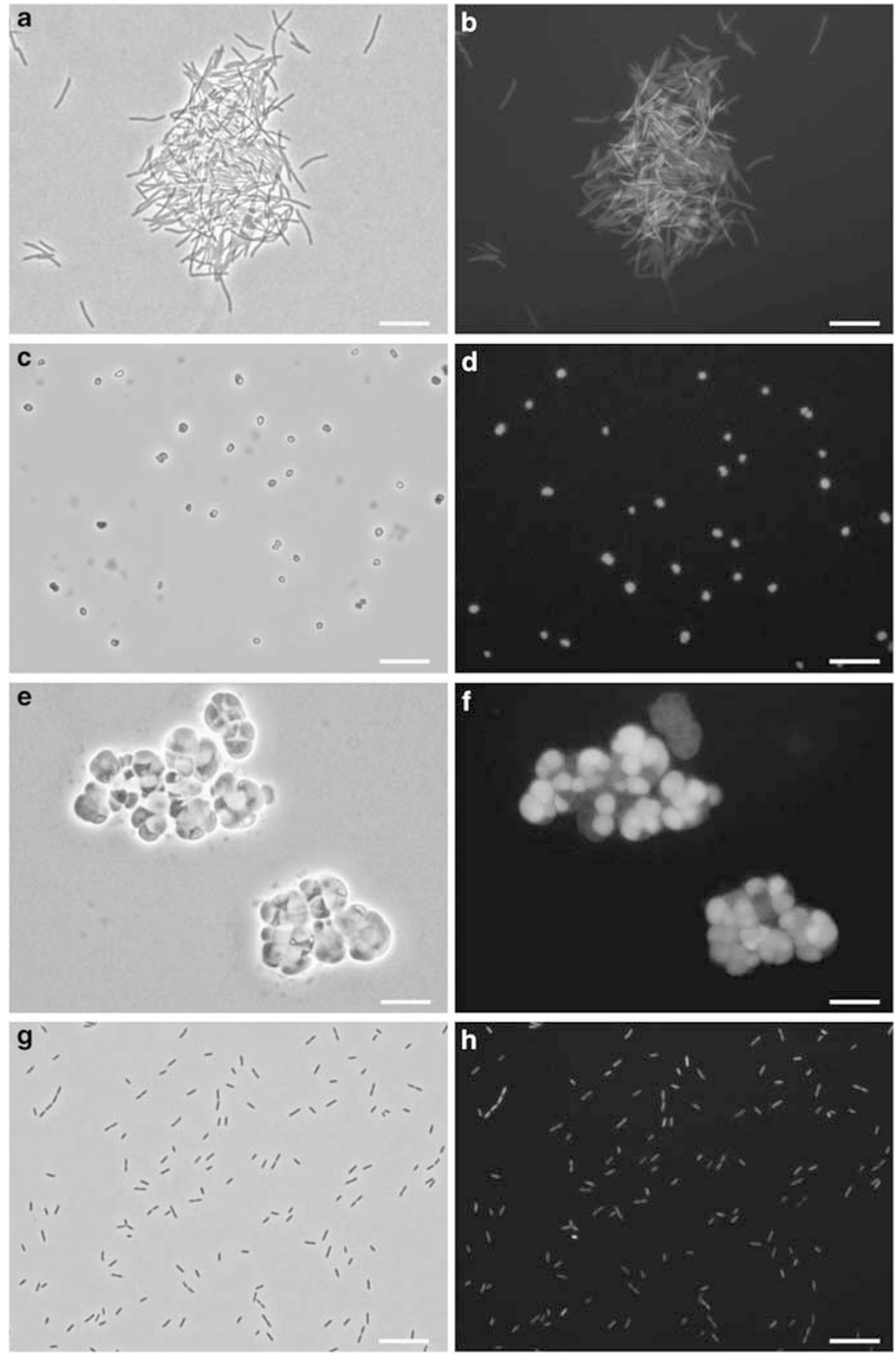

Figure 4 Photomicrographs showing cell morphologies of methanogens isolated in this study. Phase-contrast micrographs (right photos) and fluorescence micrographs (left photos) of the same fields are shown. (a, b) Strain MO-MB1, belonging to the genus Methanobacterium, grown on $\mathrm{H}_{2} / \mathrm{CO}_{2}$ medium at $25^{\circ} \mathrm{C}$; (c, d) strain MO-MS1, belonging to the genus Methanosarcina, grown on methanol medium at $25^{\circ} \mathrm{C} ;(\mathbf{e}, \mathbf{f})$ strain MO-MCD, belonging to the genus Methanococcoides, grown on trimethylamine medium at $25^{\circ} \mathrm{C}$; and (g, h) strain MO-MVB, belonging to the genus Methanobrevibacter, grown on formate plus yeast extract medium at $20^{\circ} \mathrm{C}$. Bars represent $10 \mu \mathrm{m}$.

Chemical data clearly indicated that microbial metabolism progressed in the following fashion as the DHS reactor operation progressed: (i) fermentation of glucose and yeast extract was initiated from the early stages of the reactor operation, (ii) methanogenesis occurred concomitantly with fermentation and (iii) active acetate and propionate degradations were initiated in the late stages of reactor operation (Table 1). In addition, because the $\delta^{13} \mathrm{C}$ values of methane gradually tended to be isotopically heavy as the reactor operation proceeded (Table 1), aceticlastic methanogenesis may contribute significantly to methane production following the hydrogenotrophic methanogenesis because of the smaller influence of stable carbon isotope fractionation on aceticlastic methanogens 

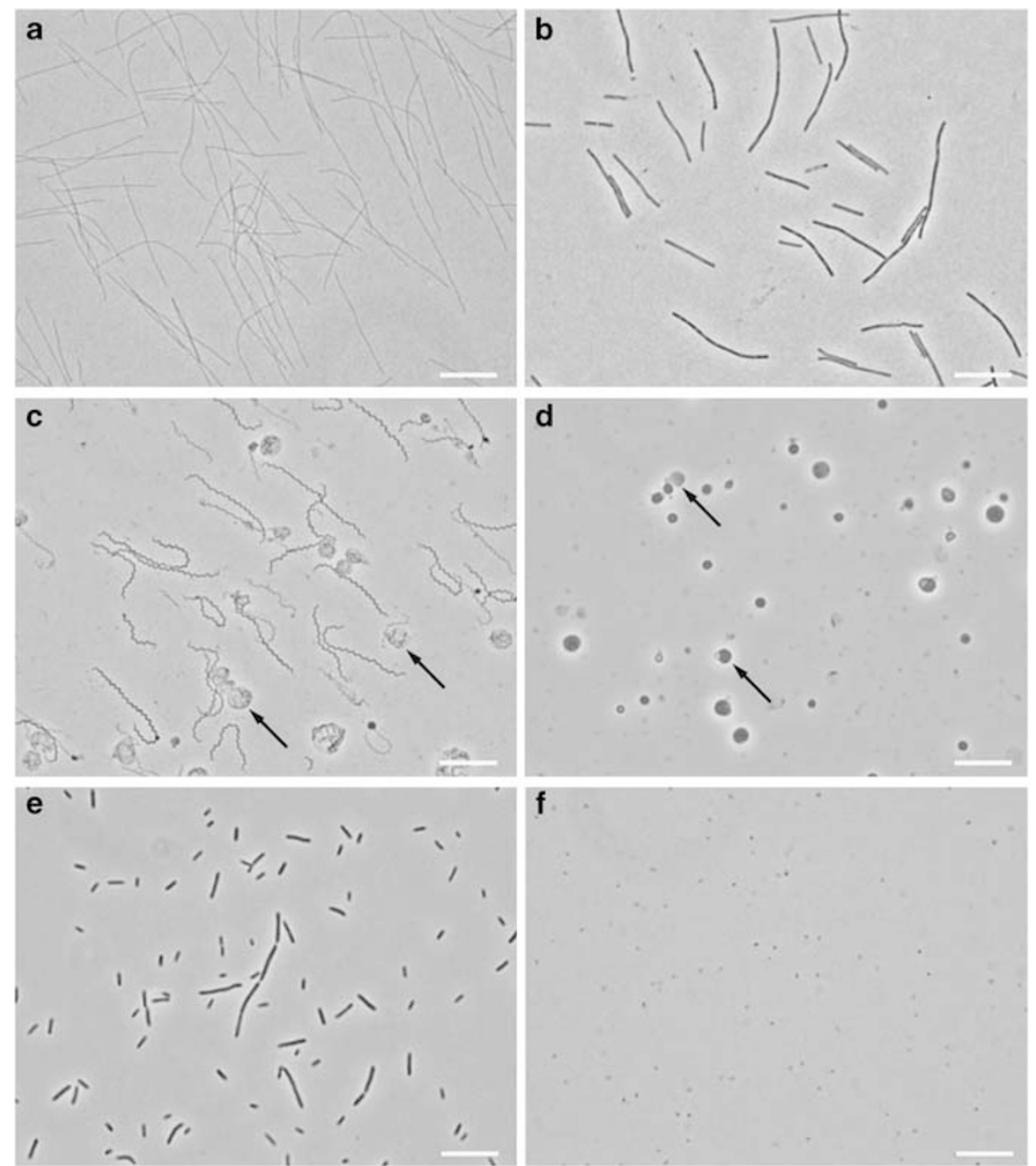

Figure 5 Phase-contrast micrographs of anaerobic bacteria isolated in this study. (a, b) Strains MO-CFX1 and MO-CFX2, belonging to the Chloroflexi subphylum I, grown on glucose plus yeast extract medium at $20^{\circ} \mathrm{C}$; (c, d) strains MO-SPC1 and MO-SPC2, belonging to the genus Spirochaeta, grown on glucose plus yeast extract medium at $10^{\circ} \mathrm{C}$. Both strains form spherical bodies that are observed in other Spirochetes species (indicated by arrows); (e) strain MO-SED, belonging to the genus Sedimentibacter, grown on yeast extract medium grown at $15^{\circ} \mathrm{C}$; and (f) strain MO-XQ, belonging to the genus Acholeplasma, grown on yeast extract medium at $25^{\circ} \mathrm{C}$. Bars represent $10 \mu \mathrm{m}$.

than on hydrogenotrophic methanogens (for example, Whiticar, 1999). This transition from hydrogenotrophic methanogenesis to aceticlastic methanogenesis is supported by several lines of evidence; (i) acetate concentrations in effluent seawater gradually decreased in the late stages of reactor operation (Table 1), (ii) the clonal frequency of the aceticlastic methanogen Methanosarcina increased with operational time (Figure 2) and (iii) an acetate-degrading enrichment culture containing a member of Methanosarcina was obtained by batch culture (AYEAV10 culture in Supplementary Table S8). On the other hand, acetate degradation can also occur via the syntrophic association of acetatedegrading bacteria and hydrogenotrophic methanogens (Hattori, 2008). In our DHS experiment, syntrophic acetate oxidation likely occurred because an acetate-degrading culture (Ace25) did not contain aceticlastic methanogen groups such as Methanosarcina but consisted of a hydrogenotrophic methanogen Methanoculleus species and several bacterial species (Supplementary Table S8).

Contrary to our expectations, the methanogen isolates from subseafloor sediments were very closely related to previously characterized (cultivated) methanogens. Although the novelty of the isolated methanogens is unfortunately low from a taxonomic perspective, our results are consistent with previous culture-independent molecular studies, which have also detected sequences closely related to previously isolated methanogens, such as Methanosarcina and Methanobrevibacter (for example, Marchesi et al., 2001; Newberry et al., 2004). Among the bacterial isolates, strains MO-CFX1 and MO-CFX2 belonging to the Chloroflexi subphylum I, and strains MO-SPC1 and MO-SPC2 belonging to the genus Spirochaeta are of note (Figures 5a-d) because these bacterial components have been frequently reported as some of the predominant microbial components in marine subsurface 
environments (for example, Toffin et al., 2004; Inagaki et al., 2006; Fry et al., 2008; Webster et al., 2009). To our knowledge, these strains are the first isolates of these bacterial groups from marine subsurface environments. In addition to these bacterial strains, strain MO-XQ (Figure $5 \mathrm{f}$ ) may be one of the major anaerobic heterotrophs in organicrich marine sediments and an ecologically significant microbial component. The most closely $16 \mathrm{~S}$ rRNA gene sequence to strain MO-XQ was found in riser-drilling mud fluids from the same drilling site offshore the Shimokita Peninsula of Japan (GenBank accession no. AB369171; 99\% sequence similarity; Masui et al., 2008). The detailed isolation procedures and physiological properties of these isolates will be reported in the near future.

Given the data presented here, the reactor method is a promising cultivation technique to cultivate subseafloor sedimentary microorganisms. In the future, we will further develop the new DHS reactor system for the successful cultivation of various uncultured subseafloor life, targeting some key biogeochemical players in Earth's carbon and nitrogen cycling. For example, in situ pressure, temperature and $\mathrm{pH}$ are significant environmental factors controlling the habitability of life in the deep biosphere. The next generation of our bioreactor system will be further improved by integrating the controllability of these geophysical and geochemical constraints into the reactor cultivation system. These are our ongoing foci.

\section{Acknowledgements}

We thank Yoshiaki Takahashi (Alt Associates, Ltd, Nagaoka, Japan) for constructing of the DHS reactor; Ai Miyashita, Yuto Yashiro, Masyuki Ehara and Dr Sanae Sakai for assistance with the DHS reactor operation; Takuya Kazawa and Taketoshi Nakamura for help in measuring organic substances; Takeshi Terada for help with Q-PCR; Drs Haruhiko Sumino and Masanobu Takahashi for providing valuable information on the DHS reactor; and Mandy Cumpston, Drs Takuro Nunoura, Satoshi Nakagawa and Hisako Hirayama for helpful discussions and comments. We greatly appreciate Professors Hideki Harada and Akiyoshi Ohashi for their continuous encouragement and support. We also thank the shipboard scientists and crews of the Chikyu Shakedown Expedition CK06-06 for helping us to collect the sediment core sample. This study was partly supported by grants from the Institute of Fermentation, Osaka, Japan, the Japan Society for the Promotion of Science, and the Ministry of Education, Culture, Sports, Science and Technology, Japan.

\section{References}

Agrawal L, Ohashi Y, Mochida E, Okui H, Ueki Y, Harada $\mathrm{H}$ et al. (1997). Treatment of raw sewage in a temperate climate using a UASB reactor and the hanging sponge cubes process. Wat Sci Technol 36: 433-440.

Altschul SF, Madden TL, Schäffer AA, Zhang J, Zhang Z, Miller W et al. (1997). Gapped BLAST and PSI-BLAST: a new generation of protein database search programs. Nucleic Acids Res 25: 3389-3402.

Aoike K, CK06-06 Scientists. (2007). D/V Chikyu Cruise Offshore Shimokita Laboratory Operation Report. Center for Deep Earth Exploration, JAMSTEC: Yokohama, Japan, http://sio7.jamstec.go.jp/JAMSTEC-exp-report/.

Colwell FS, Boyd S, Delwiche ME, Reed DW, Phelps TJ, Newby DT. (2008). Estimates of biogenic methane production rates in deep marine sediments at Hydrate Ridge, Cascadia Margin. Appl Environ Microbiol 74: 3444-3452.

D’Hondt S, Jørgensen BB, Miller DJ, Batzke A, Blake R, Cragg BA et al. (2004). Distributions of microbial activities in deep subseafloor sediments. Science 306: 2216-2221.

Fry JC, Parkes RJ, Cragg BA, Weightman AJ, Webster G. (2008). Prokaryotic biodiversity and activity in the deep subseafloor biosphere. FEMS Microbiol Ecol 66: 181-196.

Girguis PR, Cozen AE, DeLong EF. (2005). Growth and population dynamics of anaerobic methane-oxidizing archaea and sulfate-reducing bacteria in a continuousflow bioreactor. Appl Environ Microbiol 71: 3725-3733.

Girguis PR, Orphan VJ, Hallam SJ, DeLong EF. (2003). Growth and methane oxidation rates of anaerobic methanotrophic archaea in a continuous-flow bioreactor. Appl Environ Microbiol 69: 5472-5482.

Hattori S. (2008). Syntrophic acetate-oxidizing microbes in methanogenic environments. Microb Environ 23: 118-127.

Imachi H, Sakai S, Hirayama H, Nakagawa S, Nunoura T, Takai K et al. (2008). Exilispira thermophila gen. nov., sp. nov., an anaerobic, thermophilic spirochaete isolated from a deep-sea hydrothermal vent chimney. Int J Syst Evol Microbiol 58: 2258-2265.

Imachi H, Sakai S, Nagai H, Yamaguchi T, Takai K. (2009). Methanofollis ethanolicus sp. nov., an ethanol-utilizing methanogen isolated from a lotus field. Int J Syst Evol Microbiol 59: 800-805.

Imachi H, Sakai S, Ohashi A, Harada H, Hanada S, Kamagata Y et al. (2007). Pelotomaculum propionicicum sp. nov., an anaerobic, mesophilic, obligately syntrophic, propionate-oxidizing bacterium. Int J Syst Evol Microbiol 57: 1487-1492.

Imachi H, Sekiguchi Y, Kamagata Y, Loy A, Qiu YL, Hugenholtz $\mathrm{P}$ et al. (2006). Non-sulfate-reducing, syntrophic bacteria affiliated with Desulfotomaculum cluster I are widely distributed in methanogenic environments. Appl Environ Microbiol 72: 2080-2091.

Inagaki F. (2010). Deep subseafloor microbial community. In: Encyclopedia of Life Sciences. Winley \& Sons: Chichester, United Kingdom, doi: 10.1002/ 9780470015902.a0021894.

Inagaki F, Nunoura T, Nakagawa S, Teske A, Lever M, Lauer A et al. (2006). Biogeographical distribution and diversity of microbes in methane hydrate-bearing deep marine sediments on the Pacific Ocean Margin. Proc Natl Acad Sci USA 103: 2815-2820.

Inagaki F, Suzuki M, Takai K, Oida H, Sakamoto T, Aoki K et al. (2003). Microbial communities associated with geological horizons in coastal subseafloor sediments 
from the Sea of Okhotsk. Appl Environ Microbiol 69: 7224-7235.

Kendall MM, Boone DR. (2006). Cultivation of methanogens from shallow marine sediments at Hydrate Ridge, Oregon. Archaea 2: 31-38.

Kendall MM, Liu Y, Sieprawska-Lupa M, Stetter KO, Whitman WB, Boone DR. (2006). Methanococcus aeolicus sp. nov., a mesophilic, methanogenic archaeon from shallow and deep marine sediments. Int J Syst Evol Microbiol 56: 1525-1529.

Kobayashi T, Koide O, Mori K, Shimamura S, Matsuura T, Miura $\mathrm{T}$ et al. (2008). Phylogenetic and enzymatic diversity of deep subseafloor aerobic microorganisms in organics- and methane-rich sediments off Shimokita Peninsula. Extremophiles 12: 519-527.

Kubota K, Ohashi A, Imachi H, Harada H. (2006). Visualization of mcr mRNA in a methanogen by fluorescence in situ hybridization with an oligonucleotide probe and two-pass tyramide signal amplification (two-pass TSA-FISH). J Microbiol Methods 66: 521-528.

Kvenvolden K. (1995). A review of the geochemistry of methane in natural gas hydrate. Org Geochem 23: 997-1008.

Lipp JS, Morono Y, Inagaki F, Hinrichs K-U. (2008). Significant contribution of Archaea to extant biomass in marine subsurface sediments. Nature 454: 991-994.

Liu Y, Whitman WB. (2008). Metabolic, phylogenetic, and ecological diversity of the methanogenic Archaea. Ann NY Acad Sci 1125: 171-189.

Ludwig W, Strunk O, Westram R, Richter L, Meier H, Yadhukumar et al. (2004). ARB: a software environment for sequence data. Nucleic Acids Res 32: 1363-1371.

Marchesi J, Weightman A, Cragg B, Parkes R, Fry J. (2001). Methanogen and bacterial diversity and distribution in deep gas hydrate sediments from the Cascadia Margin as revealed by $16 \mathrm{~S}$ rRNA molecular analysis. FEMS Microbiol Ecol 34: 221-228.

Masui N, Morono Y, Inagaki F. (2008). Microbiological assessment of circulation mud fluids during the first operation of riser drilling by the deep-earth research vessel Chikyu. Geomicrobiol J 25: 274-282.

Meulepas RJW, Jagersma CG, Gieteling J, Buisman CJN, Stams AJM, Lens PNL. (2009). Enrichment of anaerobic methanotrophs in sulfate-reducing membrane bioreactors. Biotechnol Bioeng 104: 458-470.

Mikucki JA, Liu Y, Delwiche M, Colwell FS, Boone DR. (2003). Isolation of a methanogen from deep marine sediments that contain methane hydrates, and description of Methanoculleus submarinus sp. nov. Appl Environ Microbiol 69: 3311-3316.

Milkov A. (2004). Global estimates of hydrate-bound gas in marine sediments: How much is really out there? Earth Sci Rev 66: 183-197.

Newberry CJ, Webster G, Cragg BA, Parkes RJ, Weightman AJ, Fry JC. (2004). Diversity of prokaryotes and methanogenesis in deep subsurface sediments from the Nankai Trough, Ocean Drilling Program Leg 190. Environ Microbiol 6: 274-287.

Overpeck J, Cole J. (2006). Abrupt change in Earth's climate system. Annu Rev Environ Resour 31: 1-31.

Schink B. (1997). Energetics of syntrophic cooperation in methanogenic degradation. Microbiol Mol Biol Rev 61: 262-280.

Schoell M. (1988). Multiple origins of methane in the earth. Chem Geol 71: 1-10.

Schramm A, Fuchs BM, Nielsen JL, Tonolla M, Stahl DA. (2002). Fluorescence in situ hybridization of $16 \mathrm{~S}$ rRNA gene clones (Clone-FISH) for probe validation and screening of clone libraries. Environ Microbiol 4: 713-720.

Stams AJM, Plugge CM. (2009). Electron transfer in syntrophic communities of anaerobic bacteria and archaea. Nat Rev Microbiol 7: 568-577.

Tandukar M, Uemura S, Ohashi A, Harada H. (2006). Combining UASB and the 'fourth generation' downflow hanging sponge reactor for municipal wastewater treatment. Wat Sci Technol 53: 209-218.

Toffin L, Webster G, Weightman A, Fry J, Prieur D. (2004). Molecular monitoring of culturable bacteria from deep-sea sediment of the Nankai Trough, Leg 190 Ocean Drilling Program. FEMS Microbiol Ecol 48: 357-367.

Tomaru H, Fehn U, Lu Z, Takeuchi R, Inagaki F, Imachi H et al. (2009). Dating of dissolved iodine in pore waters from the gas hydrate occurrence offshore Shimokita Peninsula, Japan: ${ }^{129} \mathrm{I}$ results from the D/V Chikyu shakedown cruise. Resour Geol 59: 359-373.

Uemura S, Harada H. (2010). Application of UASB technology for sewage treatment with a novel post-treatment process. In: Fang HHP (ed). Environmental Aanaerobic Technology. Imperial College Press: London, United Kingdom, pp 91-112.

von Klein D, Arab H, Völker H, Thomm M. (2002). Methanosarcina baltica, sp. nov., a novel methanogen isolated from the Gotland Deep of the Baltic Sea. Extremophiles 6: 103-110.

von Wintzingerode F, Göbel UB, Stackebrandt E. (1997). Determination of microbial diversity in environmental samples: pitfalls of PCR-based rRNA analysis. FEMS Microbiol Rev 21: 213-229.

Webster G, Blazejak A, Cragg BA, Schippers A, Sass H, Rinna J et al. (2009). Subsurface microbiology and biogeochemistry of a deep, cold-water carbonate mound from the Porcupine Seabight (IODP Expedition 307). Environ Microbiol 11: 239-257.

Whiticar M. (1999). Carbon and hydrogen isotope systematics of bacterial formation and oxidation of methane. Chem Geol 161: 291-314.

Zhang Y, Henriet J-P, Bursens J, Boon N. (2010). Stimulation of in vitro anaerobic oxidation of methane rate in a continuous high-pressure bioreactor. Bioresour Technol 101: 3132-3138.

Supplementary Information accompanies the paper on The ISME Journal website (http://www.nature.com/ismej) 